Phenotype-dependent effects of EpCAM expression on growth and invasion of human breast cancer cell lines

Martowicz et al. 


\title{
Phenotype-dependent effects of EpCAM expression on growth and invasion of human breast cancer cell lines
}

Agnieszka Martowicz ${ }^{1}$ Gilbert Spizzo ${ }^{1,2}$, Guenther Gast1 ${ }^{1,3}$ and Gerold Untergasser ${ }^{3 *}$

\begin{abstract}
Background: The epithelial cell adhesion molecule (EpCAM) has been shown to be overexpressed in breast cancer and stem cells and has emerged as an attractive target for immunotherapy of breast cancer patients. This study analyzes the effects of EpCAM on breast cancer cell lines with epithelial or mesenchymal phenotype.

Methods: For this purpose, shRNA-mediated knockdown of EpCAM gene expression was performed in EpCAM ${ }^{\text {high }}$ breast cancer cell lines with epithelial phenotype (MCF-7, T47D and SkBR3). Moreover, EpCAM ${ }^{\text {low }}$ breast carcinoma cell lines with mesenchymal phenotype (MDA-MB-231, Hs578t) and inducible overexpression of EpCAM were used to study effects on proliferation, migration and in vivo growth.

Results: In comparison to non-specific silencing controls (n/s-crtl) knockdown of EpCAM (E\#2) in EpCAM ${ }^{\text {high }}$ cell lines resulted in reduced cell proliferation under serum-reduced culture conditions. Moreover, DNA synthesis under 3D culture conditions in collagen was significantly reduced. Xenografts of MCF-7 and T47D cells with knockdown of EpCAM formed smaller tumors that were less invasive. EpCAM ${ }^{\text {low }}$ cell lines with tetracycline-inducible overexpression of EpCAM showed no increased cell proliferation or migration under serum-reduced growth conditions. MDA-MB-231 xenografts with EpCAM overexpression showed reduced invasion into host tissue and more infiltrates of chicken granulocytes.

Conclusions: The role of EpCAM in breast cancer strongly depends on the epithelial or mesenchymal phenotype of tumor cells. Cancer cells with epithelial phenotype need EpCAM as a growth- and invasion-promoting factor, whereas tumor cells with a mesenchymal phenotype are independent of EpCAM in invasion processes and tumor progression. These findings might have clinical implications for EPCAM-based targeting strategies in patients with invasive breast cancer.
\end{abstract}

Keywords: EpCAM, Lentivirus, Xenografts, RNA interference, Epithelial to mesenchymal transition

\section{Background}

The epithelial cell adhesion molecule (EpCAM, CD326) is a transmembrane glycoprotein originally discovered as a colon carcinoma-associated antigen [1]. The glycosylated transmembrane protein consists of a 289 amino acid extracellular domain (EpEX) and a short 26 amino acid intracellular domain (EpICD) [2]. EpCAM localizes to the basolateral membrane in normal polarized epithelia, but in carcinoma this expression pattern changes to

\footnotetext{
*Correspondence: gerold.untergasser@i-med.ac.at

${ }^{3}$ Laboratory of Tumor Biology and Angiogenesis, Department of Internal

Medicine V, Innsbruck Medical University, Innsbruck, Austria

Full list of author information is available at the end of the article
}

an intense uniform membranous overexpression that is frequently associated with cytoplasmic staining [3]. In addition, EpCAM is hyperglycosylated to a $40 \mathrm{kDa}$ or $42 \mathrm{kDa}$ isoform in carcinoma tissue as compared with healthy autologous epithelia [4,5]. In breast carcinoma, strong EpCAM expression is observed in less differentiated tumors [6] and associates with larger tumors, nodal metastasis and poorer overall survival [6-8]. Moreover, in breast carcinoma EpCAM has been reported to be upregulated in large metastases as compared with the matched primary tumor [9]. Strong EpCAM expression has been shown to be a poor prognostic factor in both nodepositive $[8,9]$ and node-negative disease [6].

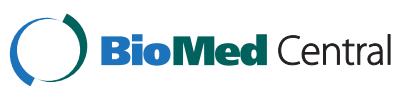


For invasion into stromal or adipose tissue breast cancer cells need to develop a mesenchymal phenotype [10]. This change in cell morphology is known as epithelial to mesenchymal transition (EMT) and seems to require downregulation of tight junction proteins, EpCAM and E-cadherin followed by re-expression at the site of the future metastasis [11]. In breast cancer, EMT has been estimated to occur in nearly $18 \%$ of tumors in vivo [12]. Under these conditions, EMT is defined as the occurrence of a variable proportion of tumor cells that express mesenchymal markers, such as vimentin and tenascin $[13,14]$.

EpCAM downregulation has already been associated with EMT $[15,16]$. Small metastases in mice with colon carcinoma were EpCAM-negative. In contrast, large metastases in the same mouse displayed a level of expression equal to that of the primary tumor, a finding that possibly reflects the re-expression at the metastatic site [17].

This study analyzed different types of breast carcinoma cells derived from metastasis for their expression of EpCAM. Based on EpCAM protein expression levels we used lentiviral systems to knock down or induce EpCAM gene expression. Knockdowns were done in epithelium-like EpCAM ${ }^{\text {high }}$ cell lines (T47D, MCF-7, and $\mathrm{SkBr} 3$ ) and inducible overexpression was performed in EpCAM $^{\text {low }}$ cell lines (Hs578t, MDA-MB-231) that display a mesenchyme-like phenotype. Our data demonstrate that EpCAM ${ }^{\text {high }}$ cancer cells with epithelial morphology clearly benefit from EpCAM overexpression with regard to proliferation and capacity to invade host tissue. In contrast, in vitro proliferation of EpCAM ${ }^{\text {low }}$ mesenchymal breast cancer cell lines is independent of EpCAM. Furthermore, we provide evidence that in vitro migration of tumor cells with mesenchymal phenotype is weakly inhibited by overexpression of EpCAM. Similar observations were made in vivo, where EpCAMoverexpressing mesenchymal tumor cells showed reduced invasive growth and more cell infiltrates of the innate immune system.

\section{Methods}

\section{Cell lines}

MCF-7, T47D and SkBR3 cell lines were purchased from the American Type Culture Collection (ATCC). All three cell lines were isolated from metastasis and display an epithelium-like phenotype. MCF-7, T47D cell lines were cultivated in MEM, Eagle's medium (PAA Laboratories $\mathrm{GmbH}$ ), and SKBR 3 in McCoy's medium (PAA Laboratories $\mathrm{GmbH}$ ) containing $10 \%$ fetal calf serum (PAA Laboratories $\mathrm{GmbH}$ ) and $100 \mathrm{IU} / \mathrm{mL}$ penicillin, $100 \mu \mathrm{g} / \mathrm{mL}$ streptomycin and $2 \mathrm{mM}$ glutamine (all PAA Laboratories $\mathrm{GmbH}) . \mathrm{MCF}-7^{\text {ns-ctrl }}, \mathrm{MCF}-7^{\mathrm{E \# 2}}$, T47D ${ }^{\text {ns-ctrl }}, T 47 \mathrm{D}^{\mathrm{E} \# 2}, \mathrm{SkBR}^{\mathrm{ns}-\mathrm{ctrl}}$ and $\mathrm{SkBR} 3^{\mathrm{E \# 2}}$ cell lines were generated by lentiviral transfection with the corresponding pGIPZ shRNA mir virus and selected with $3 \mu \mathrm{g} / \mathrm{mL}$ puromycin (Invitrogen) for 5 days in standard culture medium.

Hs578t and MDA-MB-231 cells (ATCC) originate from metastasis of human mammary carcinosarcoma and a poorly differentiated adenocarcinoma, respectively. Moreover, the latter cell type is an elongated and a highly invasive, metastatic phenotype. Hs578t and MDA-MB-231 cells were cultivated in RPMI1640 containing 10\% tetracycline-free FCS (Clontech). Parental lines of Hs578t and MDA-MB-231 were lentivirally transfected (pLENTI6/TR, Invitrogen) and selected with $1 \mathrm{mg} / \mathrm{mL}$ neomycin (Biochrom) to express the tetracycline repressor (TR) protein. Selected Hs578t ${ }^{\text {TetR }}$ and MDA-MB$231^{\text {TetR }}$ lines were lentivirally transfected (pLenti6.3 EpCAM) and stable cell lines selected with $2 \mu \mathrm{g} / \mathrm{mL}$ blasticidin (Invitrogen). Hs578t $\mathrm{t}^{\text {TetR EPCAM }}$ and MDAMB-231 $1^{\text {TetR }}$ EpCAM lines were propagated in $10 \%$ tetracycline-free FCS (Clontech).

Immortalized non-tumorigenic human mammary epithelial cells (MCF-10A) were obtained from the ATCC and cultivated Dulbecco's modified Eagle's medium F12 (DMEM/F12) supplemented with 5\% horse serum (both Invitrogen), 1\% penicillin/streptomycin (all PAA Laboratories $\mathrm{GmbH}$ ), $0.5 \mu \mathrm{g} / \mathrm{mL}$ hydrocortisone, $10 \mu \mathrm{g} / \mathrm{mL}$ insulin and $20 \mathrm{ng} / \mathrm{mL}$ recombinant human EGF (all Sigma Biochemicals). Human Mammary Epithelial Cells (HMECs) were purchased from Promocell. HMECs were cultivated in Mammary Epithelial Cell Growth Medium with recommended supplements (Promocell, $0.004 \mathrm{~mL} / \mathrm{mL}$ Bovine Pituitary Extract, $10 \mathrm{ng} / \mathrm{mL}$ epidermal growth factor, $5 \mu \mathrm{g} / \mathrm{mL}$ insulin and $0.5 \mu \mathrm{g} / \mathrm{mL}$ hydrocortisone) on collagen type I (Sigma Biochemicals) -coated ventilated plastic flasks.

\section{Immunohistochemistry}

Tissue sections were deparaffinized and hydrated in xylene and graded alcohol series. Antigen retrieval was performed in a water bath $\left(95^{\circ} \mathrm{C}\right)$ for 20 min with a target retrieval solution (Dako Cytomation), and endogenous peroxidase activity was blocked with $3 \% \mathrm{H}_{2} \mathrm{O}_{2} /$ methanol. Sections were incubated in blocking solution containing $10 \%$ fetal calf serum (Dako Cytomation) for $45 \mathrm{~min}$ and then stained for one hour with primary antibody (mouse anti-human EpCAM, ESA, clone VU-1D9, Novocastra, $1 \mu \mathrm{g} / \mathrm{mL})$. Moreover, serial sections were incubated with an alpha smooth muscle cell actin (clone 1A4; 1:100, Sigma Biochemicals) or Ki67 (clone MIB-1, Dako Cytomation), or desmin (clone CD33, Dako), or vimentin (clone V9, Dako), or E-cadherin (clone 32A8, Cell Signaling Technology). Primary antiserum was detected after incubation with a biotinylated secondary antibody (biotinylated rabbit anti-mouse IgG, Vector Laboratories Inc.) using the Vectastain Elite ABC Kit (Vector Laboratories Inc.) and the FAST DAB Tablet Set 
(Sigma Biochemicals). Sections were counterstained with Meyer's hematoxylin and mounted with Pertex (Medite).

\section{Immunofluorescence}

Cells were seeded on eight-well culture chamber slides (Falcon BD Labware) at densities of 20,000 cells/well and incubated overnight in $5 \% \mathrm{CO}_{2}$ at $37^{\circ} \mathrm{C}$. After being fixed in $4 \%$ paraformaldehyde and permeabilized with $0.2 \%$ Triton-X-100 cells were blocked with PBS containing 3\% BSA for $45 \mathrm{~min}$ at room temperature (RT). E-cadherin- (clone 32A8, Cell Signaling Technology), vimentin- (clone v9, Dako Cytomation), and cytokeratin 18- (clone DC 10, Dako) specific antibodies were applied in a 1:200 dilution at RT for two hours. After washing in PBS cells were incubated with secondary fluorochromelabeled antibodies (FITC-labeled rabbit anti-mouse, Dako Cytomation) and nuclei were counterstained with DAPI (Molecular Probes). Cells were embedded in fluorescent mounting medium (Dako Cytomation) and viewed with constant laser settings using a fluorescence microscope (Zeiss Axiovert 200M with Axiovision 4.7 Software, Carl Zeiss Optics).

\section{Western Blot analysis}

Cells were harvested and lysed in an RIPA buffer (Sigma) containing protease inhibitors (Complete Mini EDTA-free; Roche Applied Science). Total protein $(20 \mu \mathrm{g})$ was denaturated, separated by a 4\%-20\% SDS-PAGE (Criterion TGX, Bio-Rad) and transferred to Immuno-Blot ${ }^{\mathrm{TM}}$ polyvinylidene difluoride (PVDF) membrane (Bio-Rad). After blocking the membrane in $5 \%$ non-fat milk powder dissolved in phosphate-buffered saline (PBS), membranes were incubated overnight in $0.5 \%$ non-fat milk powder at $4^{\circ} \mathrm{C}$ with primary mouse antibodies. Antibodies used for Western Blot analysis were a mouse monoclonal directed against EpCAM (C-10; Santa Cruz Biotechnology) and a mouse monoclonal against alpha tubulin (clone B5-1-2; Sigma Biochemicals). Afterwards, membranes were incubated for one hour with an HRP-conjugated goat anti-mouse IgG (Dako Cytomation) diluted 1:1,000. After washing, a chemoluminescent substrate (LumiGLO Reagent and Peroxide, Cell Signaling Technology) was added to the membrane, which was then exposed in the Chemidoc XRS station (Biorad Laboratories). Different glycosylated isoforms of EpCAM were analyzed by Western Blot after deglycosylating the protein in RIPA buffer by means of PNGase F and Endo H (both from New England Biolabs). Band intensities were analyzed and calculated using the Quantity One 4.6 software (BioRad Laboratories).

\section{Generation of lentiviral particles for knockdown and overexpression of EpCAM}

Three lentiviral transfer vectors (pGIPZ shRNAmir) targeting different regions of the EPCAM open reading frame (clone Ids: V2LHS_134162, V2LHS_134158, V2LHS_23265) and validated non-silencing control (ns-ctrl; RHS4346) were ordered from Open Biosystems. pGIPZ clones were propagated in the presence of $25 \mu \mathrm{g} / \mathrm{ml}$ zeocin (Invitrogen) and plasmids purified with the highspeed Plasmid MIDI Kit (Qiagen). Lentiviral particles were produced by transfecting HEK 293FT cells (Invitrogen) with helper plasmid mix (trans-lentiviral packaging system, Open Biosystems) and Lipofectamin 2000 (Invitrogen).

The EpCAM cDNA (NM_002354, Open Biosystems) was subcloned into the Gateway pENTR11dual section vector (Invitrogen). The pENTR11 vector was sitespecifically recombined with the pDEST6.3 vector (Invitrogen) using the Gateway LR Clonase II Pus Enzyme Mix (Invitrogen). The resulting pDEST6.3 vector with the EpCAM open-reading frame was transformed and propagated in One-Shot Stabl3 bacteria (Invitrogen). Lentiviruses were produced in HEK 293FT cells (Invitrogen) by transfecting cells with the pDEST6.3 EpCAM vector and helper plasmid mix (ViraPower, lentiviral support kit, Invitrogen) using Lipofectamine 2000. Lentiviral titers were determined by real time PCR and quantification of woodchuck hepatitis virus posttranscriptional response element expression (WPRE-for: 5-actgacaattccgtggtgtt; WPRE-rev: 5-agatccgactcgtct gagg), as described elsewhere [18].

\section{Quantitative RT-PCR analysis}

Total RNA was isolated from all cell lines using the TriReagent (Sigma Aldrich), according to the manufacturer's instructions. Thereafter, viral and genomic DNA in the RNA samples was digested with the RQ1 DNAse (Promega). The cDNA was amplified from $1 \mu \mathrm{g}$ total RNA using the SuperScript II Reverse Transcriptase Kit (Invitrogen Life Technologies). For validation, real time RT-PCR was performed using a SensiMix SYBR No-ROX Kit (Bioline) and a Rotor-Gene 6000 detection system (Corbett Research). Primers were designed to amplify human-specific GAPDH (for: 5-ctgacctgccgtctagaaaa; rev: 5-gagcttgacaaagtggtcgt), TATA-Box binding protein (for: 5- ggagccaagagtgaagaaca; rev: 5-agcacaaggccttctaacct) and EpCAM (for: 5-gctggtgtgtgaacactgct; rev: 5acgcgttgtgatctccttct).

\section{Real time cell proliferation and migration assay (xCelligence system)}

Real time cell proliferation and migration experiments were performed using the RTCA DP instrument (Roche Diagnostics $\mathrm{GmbH}$ ), which was placed in a humidified incubator maintained at $5 \% \mathrm{CO}_{2}$ and $37^{\circ} \mathrm{C}$. For proliferation assays cells were seeded in complete medium in 16-well plates (E-plate 16, Roche Diagnostics $\mathrm{GmbH}$ ) at a density of 5,000 cells/well. The plate, which contained gold microelectrodes on its bottom, was monitored every ten 
minutes for four hours (adhesion process), then once every $30 \mathrm{~min}$ until the end of the experiment, (72h). Cell migration was performed using special 16-well plates with $8-\mu \mathrm{m}$ pores (CIM plate 16, Roche Diagnostics $\mathrm{GmbH}$ ). These plates, resembling conventional transwells, have microelectrodes on the underside of the membrane, which is located between an upper and a lower chamber. Cells were seeded into the upper chamber at a density of 20,000 cells/well in a serum-free medium. Lower chambers were filled with complete medium. The plate was monitored every $15 \mathrm{~min}$ for $12 \mathrm{~h}$. Data analysis was performed using the RTCA software 1.2 supplied with the instrument (Roche Diagnostics).

\section{D tumor collagen plug formation}

The ice-cold collagen type I solution was obtained by mixing on ice 8.2 volumes of rat-tail collagen type I (2.0 $\mathrm{mg} / \mathrm{ml}$, Sigma Aldrich), 1 volume of MEM 10x concentrated medium and 0.8 volumes of sterile $0.2 \mathrm{M}$ $\mathrm{NaOH}$; $\mathrm{pH}$ was adjusted to 7.4 with sterile $\mathrm{NaOH}$. 3D collagen drop cultures were generated by resuspending $5.0 \times$ $10^{5}$ breast cancer cells in $30 \mu \mathrm{l}$ collagen mix. Hs578t $\mathrm{t}^{\mathrm{TetR}}$ EpCAM and MDA-MB-231 TetR EpCAM cells were additionally stimulated with tetracycline $(1 \mu \mathrm{g} / \mathrm{mL})$. Then $30 \mathrm{\mu l}$ collagen drops were dropped into a sterile $10-\mathrm{cm}, \varnothing$ cell culture dish (Falcon) coated with sterilized parafilm and allowed to polymerize for $30 \mathrm{~min}$ at $37^{\circ} \mathrm{C}$ in a humidified cell culture incubator. After polymerization of 3D cultures, collagen plugs were either transferred into 96-well plates (1 plug/well) and maintained in a $200 \mu \mathrm{L}$ standard complete cell culture medium for $3 \mathrm{D}$ in vitro cell proliferation experiments or directly grafted on a chicken CAM for in vivo tumor growth studies.

\section{D proliferation assay}

MCF-7 ${ }^{\text {ns/ctrl }}$, MCF- $^{\mathrm{E} \# 2}, \mathrm{~T}^{\mathrm{A}} 47 \mathrm{D}^{\mathrm{ns} / \mathrm{ctrl}}, \mathrm{T}-47 \mathrm{D}^{\mathrm{E} \# 2}, \mathrm{SkBR} 3^{\mathrm{ns} / \mathrm{ctrl}}$, $\mathrm{SkBR} 3^{\mathrm{E} \# 2}$ or $\mathrm{Hs} 578 \mathrm{t}^{\mathrm{TetR} \text { EpCAM }}$ or MDA-MB-231 ${ }^{\text {TetR EpCAM }}$ were grown in 96-well plates in the presence of $2.5 \%$ serum. Hs578t $\mathrm{t}^{\text {TetR EpCAM }}$ or MDA-MB-231 ${ }^{\text {TetR EpCAM }}$ was cultivated in complete medium with or without $1 \mu \mathrm{g} / \mathrm{mL}$ tetracycline. After three days of in vitro growth a cell proliferation assay was performed (BrdU ELISA kit, GE Healthcare). Cells were pulsed with 5-bromo-2'-deoxyuridine $20 \mathrm{~h}$ prior to measurement in ELISA. Microplates with cell plugs were centrifuged at 2,000 $\mathrm{g}$ to allow the plugs to attach to the bottom of the plate. Thereafter, cells in plugs were fixed with the fixative solution and the ELISA performed according to the manufacturer instructions.

\section{Chicken chorioallantoic membrane (CAM) tumor xenograft model}

On embryo development day 0 fertilized chicken eggs (Gallus domesticus) were placed in a 75\%-80\% humidified $37^{\circ} \mathrm{C}$ incubator to allow normal embryo development. On day 3 eggs were opened, egg shells removed and embryos were placed in a sterile Petri dish in an egg incubator (Grumbach) to induce CAM development. Embryos were inspected daily until the day of experiment. On day 8, when the chorioallantoic membrane (CAM) and its vasculature were well developed, the experiment was performed. Subsequently, four onplants (collagen cell plugs) per chicken were grafted onto the CAM. Growth of tumor xenografts was inspected on a daily basis using a stereo fluorescence microscope (Olympus SZW 10). On day 6 post-grafting chicken embryos were sacrificed by hypothermia, xenografts/CAM cut out and stored in $4 \%$ paraformaldehyde (Sigma Biochemicals) for immunohistochemistry or in TRI reagent (Sigma Biochemicals) for RNA isolation.

\section{Statistical analyses}

Statistical analyses were performed with the GraphPad Prism $^{\mathrm{TM}}$ software 5.0 (GraphPad Software, Inc.). All tests of statistical significance were two-sided. Student's $T$ test and the Mann-Whitney $U$ Test were used to study differences between two groups. Statistical analyses of quantitative PCR data were performed according to the delta Ct method described by Pfaffl et al. [19] and $p$ values were calculated with Student's $T$ test or the two-way ANOVA test.

\section{Results}

Expression of EpCAM in breast cancer cell lines and primary human mammary epithelial cells

EpCAM gene and protein expression was analyzed in various breast cancer cell lines, immortalized (MCF10A) and normal mammary epithelial cells (HMECs). Normal and immortalized cells showed no detectable protein in Western Blot analysis (Figure 1A/B). The same holds true for the mesenchyme-like breast cancer cell lines MDA-MB-231 and Hs578t (Figure 1A/B). By contrast, epithelium-like tumor cell lines MCF-7, T47D, and SkBR3 showed strong expression of the EpCAM protein as basic and glycosylated isoforms of 35 and 40 $\mathrm{KDa}$ (Figure 1A). Western Blot results were confirmed by real-time PCR (Figure 1C). Epithelial breast carcinoma cell lines had significantly stronger EpCAM gene expression than did HMECs or immortalized MCF-10A mammary epithelial cells. Mesenchymal MDA-MA-231 and Hs578t displayed low amounts of EpCAM mRNA (Figure 1C). Based on these findings $\mathrm{EpCAM}^{\text {high }}$ and EpCAM $^{\text {low }}$ breast cancer cell lines were phenotyped for markers of epithelial or mesenchymal differentiation. MCF-7 and T47D cells with strong EpCAM expression were strongly positive for epithelial markers cytokeratin 18 and E-cadherin and negative for mesenchymal vimentin expression as determined by immunofluorescence analysis (Figure 1D). In contrast, Hs578t and MDA-MB-231 


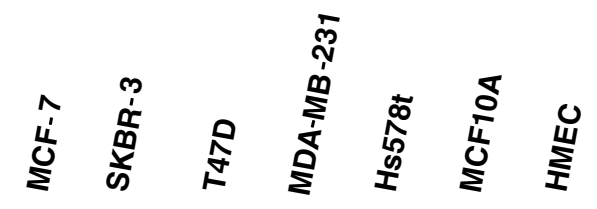

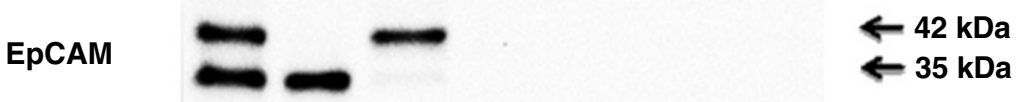

tubulin

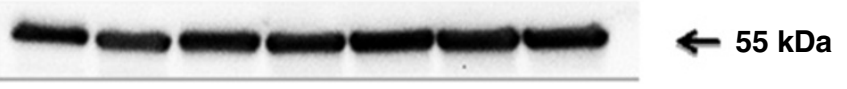

\section{B}

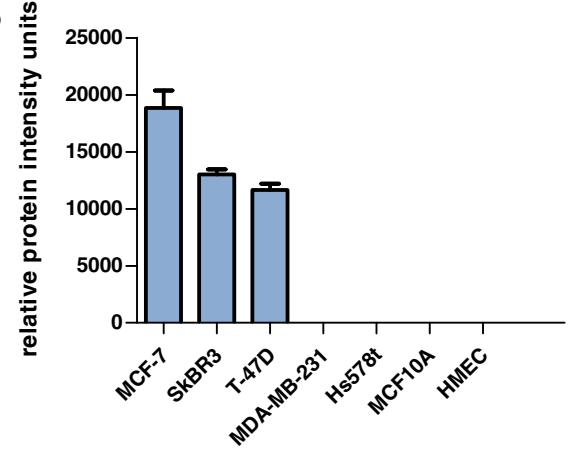

C

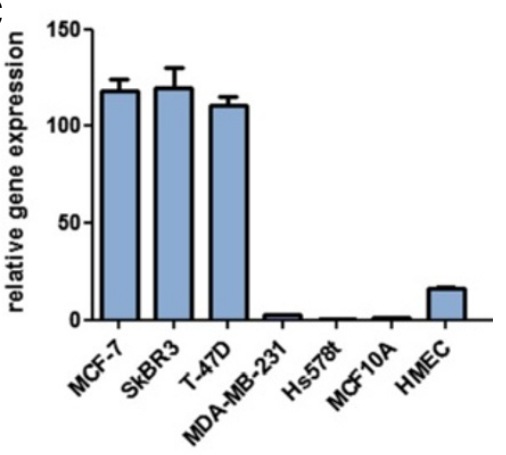

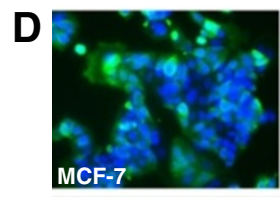
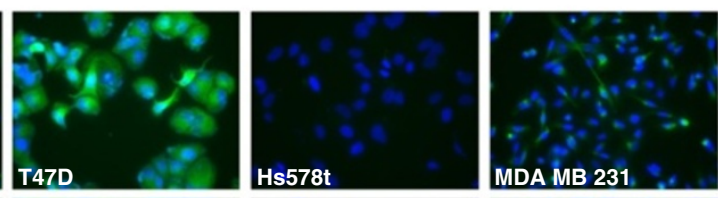

Cytokeratin
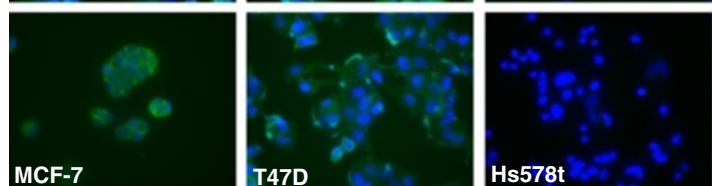

MDA MB 23

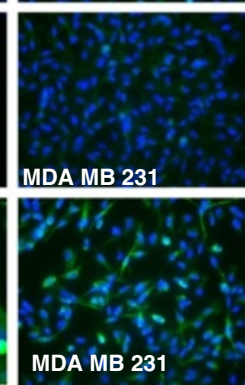

E-cadherin

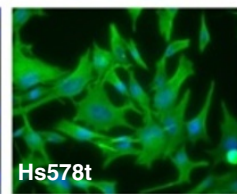

MDA MB 23

Figure 1 Expression of EpCAM in human breast cancer cell lines and primary epithelial cells. (A) Protein expression was analyzed by Western Blot analysis with an antibody directed against the extracellular domain of EpCAM. Primary cells (HMECs) showed weak or no expression of EpCAM. Epithelial tumor cells displayed strong EpCAM expression, whereas EpCAM expression decreased in more mesenchymal tumor cells. The two different bands represent glycosylated and basic isoforms of EpCAM. Tubulin served as internal loading control. (B) Densitometric analysis of EpCAM protein expression of two independent experiments. Values indicate relative intensity units. (C) EpCAM gene expression was analyzed by real-time PCR analysis using TATA-Box binding protein and GAPDH as internal housekeeping genes. All cell lines were analyzed in triplicate and normalized to the expression levels of MCF-10A cells. (D) Tumor cell lines were phenotyped by immunofluorescence analysis after staining for epithelial markers cytokeratin-18 and E-cadherin and the mesenchymal marker vimentin. Magnification 400x.

cells with low EpCAM expression were strongly positive for the mesenchymal marker vimentin and negative or weakly positive for E-cadherin and cytokeratin 18. Hs578t cells were more transdifferentiated to mesenchymal cancer cells and more fibroblast-like than MDA-MB-231 (Figure 1D).
Knockdown of EpCAM inhibited cell proliferation of epithelium-like EpCAM ${ }^{\text {high }}$ breast cancer cells in vitro Based on our previous analysis of EpCAM expression in epithelium- and mesenchyme-like breast carcinoma cell lines we selected three EpCAM ${ }^{\text {high }}$ cell lines for lentiviral knockdown studies, i.e. T47D with a strongly glycosylated, 
MCF-7 with basic and glycosylated, SkBR-3 with only basic EpCAM isoform (Figure 1A). Glycosylation patterns were analyzed after deglycosylating all EpCAM isoforms by means of endoglycosidases to a $35 \mathrm{kDa}$ not glycosylated isoform (data not shown). EpCAM-high cell lines were lentivirally transfected to express a non-silencing control (n/s ctrl) or EpCAM-specific shRNA together with turbo GFP and a puromycin resistance gene (Figure 2A). Three different sequences, E\#1, E\#2 and E\#3 targeting the open reading frame (ORF) of EpCAM, were pretested (data not shown) and the E\#2 sequence giving the best knockdown was used for further studies. Effective knockdown was controlled by real-time PCR on all three cell lines (Figure 2B) and by Western Blot analysis (Figure 2C). Lentivirally transfected cells were selected for five days with puromycin and subsequently used for analysis of cell proliferation. In comparison to n/s ctrl cells, E\#2 knockdown cells displayed a significantly lower capacity to proliferate in vitro after seeding the same starting amount of cells into the $\mathrm{xCelligence}$ real-time cell counting system (Figure 2D). These observations were made in all three cell lines under serum-reduced conditions, i.e. $2.5 \%$ serum, over the observed time period of three days. The pro-survival effect of EpCAM was less pronounced under full mitotic conditions, i.e. $10 \%$ serum in the culture medium (data not shown). Additionally, cell proliferation was analyzed by measuring DNA synthesis, i.e. BrdU incorporation, under $3 \mathrm{D}$ culture conditions in collagen drops with tumor cells. All used cell lines displayed a significant reduction in DNA synthesis after knockdown of EpCAM within three days of in vitro growth (Figure $2 \mathrm{E}$ ).

\section{Knockdown of EpCAM inhibits invasion of epithelium-like EpCAM $^{\text {high }}$ breast cancer cell xenografts}

Based on our in vitro results we aimed to study the effects of EpCAM knockdown in the in vivo situation. For this purpose, we selected the chicken chorioallantoic membrane (CAM) xenograft model that allows us to study human cells in an animal microenvironment [20,21]. Chicken embryos have only innate immune responses and tolerate growth of human cancer cells for a period of six days when cells are transplanted on the surface of the CAM tissue (Figure 3A). MCF-7 and T47D onplants can be observed daily by stereo-fluorescence microscopy due to expression of turbo GFP (Figure 3B). SkBr3 cells failed to form vascularized tumors that invade the CAM (data not shown). Macroscopically, MCF7 and T47D tumors did not differ in size when analyzing and calculating only surface areas on CAMs. Immunohistochemical analysis of tumor cells by the proliferation marker Ki67 revealed that knockdown of EpCAM significantly affected tumor cell invasion into host tissue (Figure $3 \mathrm{C}$ ). Knockdown of EpCAM strongly reduced the invasion capacity of MCF-7 and T47D tumor cells in chicken tissue (Figure 3C, yellow line and arrows). Moreover, as determined by staining for mesenchymal cells, such as pericytes (desmin) and smooth muscle cells of chicken blood vessels (ASMA), reactive responses of the chicken stroma to the invading tumor cell front were nearly abolished (Figure 3C).

\section{Overexpression of EpCAM does not support proliferation or migration of mesenchyme-like EpCAM ${ }^{\text {low }}$ breast cancer cells in vitro}

Based on our previous analysis on EpCAM expression in epithelium- and mesenchyme-like breast carcinoma cell lines (Figure 1) we selected two EpCAM ${ }^{\text {low }}$ cell lines for inducible lentiviral overexpression studies, i.e. MDA-MB-231 and Hs578t breast carcinoma cells, both with a mesenchymal cancer phenotype (Figure 1D). Cells were lentivirally transfected to express the bacterial tetracycline-repressor protein (TET-R) and selected with neomycin for ten days. Thereafter, MDA-MB-231 ${ }^{\text {TetR }}$ and $\mathrm{Hs} 578 \mathrm{t}^{\text {TetR }}$ cell lines were lentivirally transfected with an EpCAM open reading frame under a tetracycline-repressible CMV promoter (Figure 4A) and short-time selected with blasticidin. Both cell lines, MDA-MB-231 ${ }^{\text {TetR EpCAM }}$ and Hs578t ${ }^{\text {TetR }}$ EpCAM, were tested for tetracycline-induced expression of EpCAM by real-time PCR (Figure 4B). In comparison to cells growing without tetracycline and having low endogenous transcript levels, addition of tetracycline induced a 20- to 30-fold expression of the EpCAM gene. In addition to gene expression, we also analyzed the induction of EpCAM protein expression by Western Blot analysis (Figure 4C). In both cell lines, MDA-MB-231 ${ }^{\text {TetR }}$ EpCAM and Hs578t ${ }^{\text {TetR EpCAM }}$, we observed a strong induction of EpCAM protein already $24 \mathrm{~h}$ after adding tetracycline to the culture medium (Figure 4D). It is noteworthy that both cell lines produced predominantly the glycosylated $(40 \mathrm{kDa})$ isoform and, to a minor extent, also the hyperglycosylated isoform $(42 \mathrm{kDa})$. Tetracyclineinducible EpCAM cell lines were used for analysis of in vitro cell proliferation in the $\mathrm{xCelligence} \mathrm{system.} \mathrm{Induc-}$ tion of EpCAM by tetracycline had no statistically significant effect on cell proliferation within an observed time period of three days (Figure 5A). Since Hs578t as well as MDA-MB-231 cells show a high capacity to migrate, we studied the effects of EpCAM on in vitro cell migration. Cells were pre-incubated for $24 \mathrm{~h}$ with tetracycline, counted and then transferred into the xCelligence real-time cell migration system. Induction of EpCAM by tetracycline did not affect in vitro cell migration within an observed period of $12 \mathrm{~h}$ in MDA-MB-231 cells (Figure 5B). In contrast, the fibroblast-resembling Hs578t cells were significantly inhibited in cell migration after overexpression of EpCAM (Figure 5B). Analyses of DNA synthesis in the BrdU incorporation assay of $3 \mathrm{D}$ collagen drop cultures also did not reveal significant differences in in vitro cell proliferation, three days after induction of EpCAM (Figure 5C). 

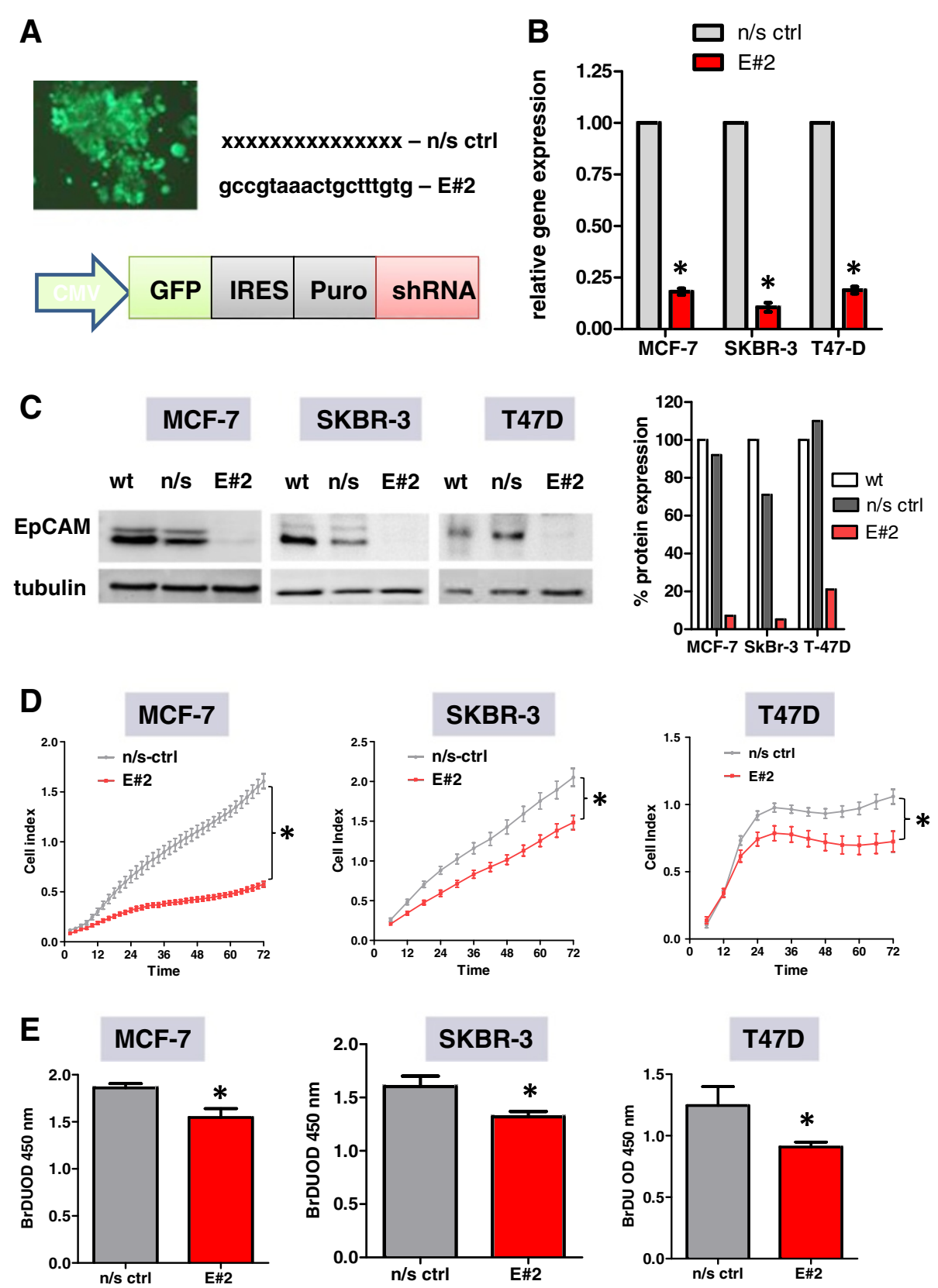

Figure 2 Lentiviral knockdown of EpCAM gene expression by shRNA in EpCAM ${ }^{\text {high }}$ human breast cancer cell lines. (A) Lentiviruses were generated that express not only the green fluorescent protein (GFP) and the puromycin resistance gene (Puro), but also shRNAs targeting EpCAM (E\#2) or a non-silencing control sequence ( $\mathrm{n} / \mathrm{s}$ ctrl). Transfected cells expressed turbo GFP and were selected with puromycin for five days. (B) The efficacy of EpCAM knockdown (E\#2) in comparison to that of non-silencing controls ( $\mathrm{n} / \mathrm{s} \mathrm{ctrl}$ ) was proven by real-time PCR. Gene expression was reduced below $20 \%$ of the control value in all three cell lines analyzed. All cell types were analyzed in triplicate. (C) Knockdown of EpCAM was proven on the protein level by Western Blot analysis. Tubulin alpha served as internal loading control. In comparison to wild-type cells (wt) and $\mathrm{n} / \mathrm{s}$ ctrl, EpCAM expression decreased in cells expressing E\#2. Densitometric analysis of two independent experiments (means) as compared to wild type expression (100\%). (D) Proliferation of transfected cells was monitored in real-time by the xCelligence system over a period of $72 \mathrm{~h}$. E\#2-expressing cells displayed significantly less proliferation and a smaller cell number when cultivated under serum-reduced conditions ( $n=6$ ). (E) 3D growth of transfected cells was studied in collagen plugs by incorporating BrdU and subsequently measuring BrdU in a specific ELISA. E\#2-expressing cells showed a significantly lower rate of DNA synthesis $(n=6)$. Stars indicate $p$ values $<0.05$. 

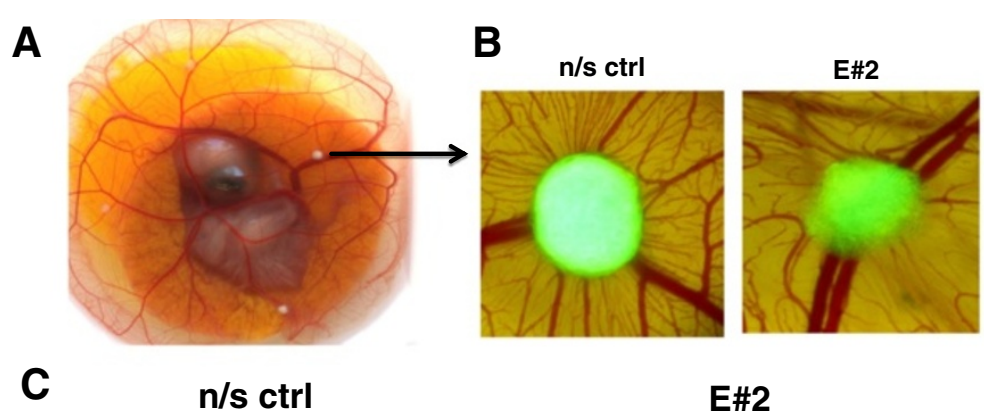

$\mathrm{n} / \mathrm{s}$ ctrl

\section{E\#2}
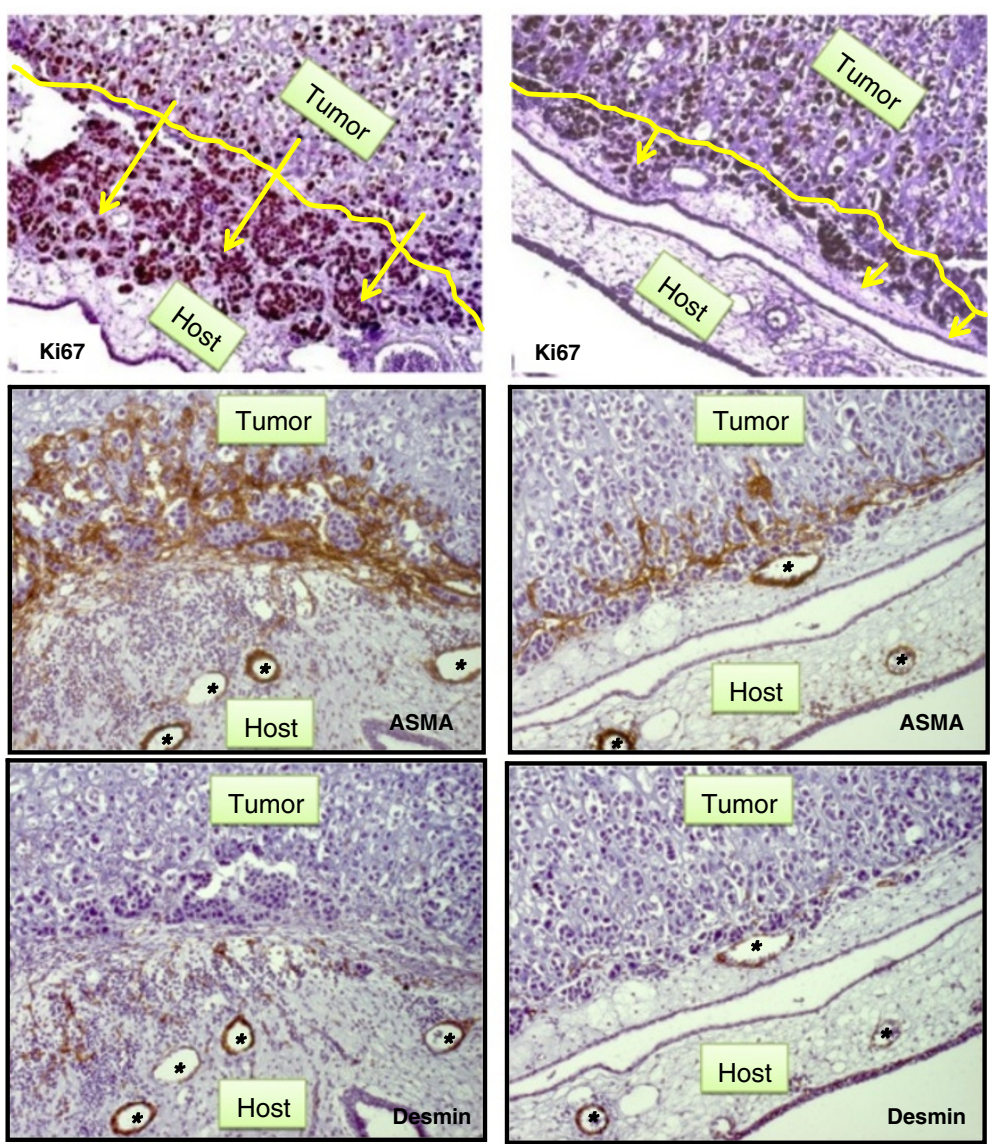

Figure 3 Effects of lentiviral knockdown of EpCAM on in vivo growth and invasion of EpCAM ${ }^{\text {high }}$ breast cancer cell lines. (A) In vivo growth of MCF-7 breast cancer cell xenografts in the chicken chorioallantoic membrane model (CAM). Magnification 1x. (B) Xenografts form tumors (arrow) that can be monitored due to expression of GFP by stereo-fluorescence microscopy. Within six days of observation tumors grew inside the CAM and attracted and co-opted blood vessels. Magnification 20x. (C) Immunohistochemical analysis of tumor xenografts in the host tissue. Brown color indicates a positive reaction. All nuclei were counterstained with hematoxylin (blue). Proliferating tumor cells were stained for the nuclear antigen Ki67, mural cells of blood vessels (myofibroblasts) with alpha smooth muscle cell actin (ASMA) or pericytes (fibroblasts) with desmin.

Knockdown of EpCAM (E\#2) resulted in tumors with less invasion and proliferation in host tissue and in a reduction of stromal responses to the tumor. Yellow arrows indicate invading tumor cell clusters and yellow lines borders between xenograft and host tissue. (Magnification 200x). In vivo experiments were performed with at least 12 embryos per group and 4 onplants/CAM. Asterisks indicate blood vessels of the underlying CAM.

\section{EpCAM downregulates E-cadherin gene expression in} mesenchyme-like EpCAM ${ }^{\text {low }}$ breast cancer cells

Depending on cell culture conditions and the respective microenvironment, MDA-MB 231 cells with parentally low EpCAM and E-cadherin expression can induce endogenous transcription of both genes (Figure 6A/B). The MDA-MB-231 cell line, when growing under 3D culture conditions, displayed larger amounts of EpCAM and E-cadherin than under standard 2-D culture conditions. Transcript levels of E-cadherin and EpCAM were even more elevated under in vivo culture conditions in the CAM.

Interestingly, tetracycline-induced overexpression of EpCAM in MDA-MB-231 cells was responsible for 
B

A

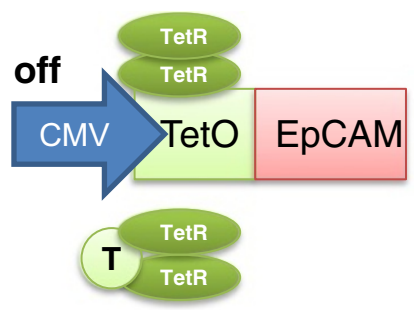

on

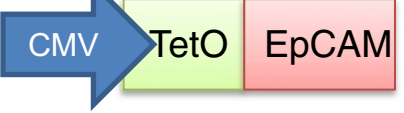

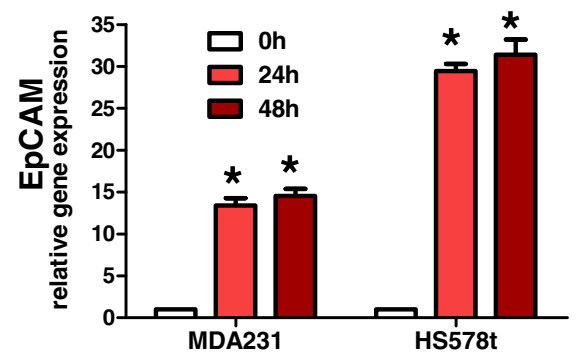

D

\section{C}

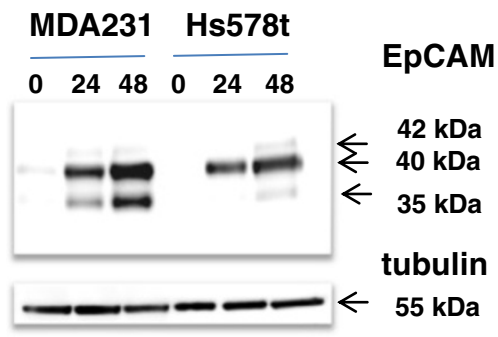

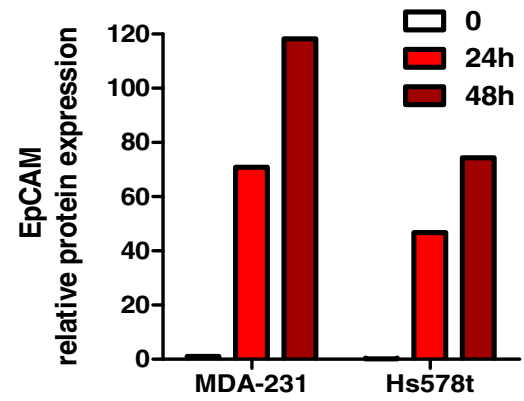

Figure 4 Inducible overexpression of EpCAM in EpCAM $^{\text {low }}$ human breast cancer cell lines with mesenchymal phenotype. (A) EpCAM ${ }^{\text {low }}$ cell lines MDA-MB-231 and Hs578t were transfected to express the tetracycline-repressor protein (TetR). A lentiviral construct for tetracycline (T)-inducible expression of EpCAM was generated and tumor cells stably integrating the construct were selected and named Hs578t $\mathrm{t}^{\mathrm{TetR}} \mathrm{EPCAM}$ or MDA-MB-231 TetR EpCAM . (B) Stimulation with tetracycline for $24 \mathrm{~h}$ resulted in a strong induction of EpCAM gene expression as determined by realtime PCR. Mean \pm SEM of three independent experiments. (C) Moreover, upregulation of EpCAM was observed on the protein level as determined by Western Blot analysis. In addition to the unglycosylated protein, EpCAM was produced as a glycosylated and hyperglycosylated isoform in both cell lines analyzed. (D) Densitometric analysis of EpCAM protein expression of two independent experiments. All means are calculated in comparison to expression of MDA-MB 231 cells before induction with tetracycline.

downregulation of E-cadherin gene expression, namely under 3D conditions and in the CAM in vivo.

\section{MDA-MB-231 xenografts with EpCAM overexpression display reduced invasion into host tissue and strong innate immune responses}

Hs578t ${ }^{\text {TetR EpCAM }}$ cells could not be used in the chicken CAM xenograft model, because they did not invade CAM tissue, lacked neovascularization and displayed many apoptotic cells due to lack of oxygen and nutrients (data not shown). Consequently, experiments were performed with the highly invasive MDA-MB- $231^{\text {TetR EpCAM }}$ cells. MDA-MB-231 ${ }^{\text {TetR EPCAM }}$ cells have low endogenous EpCAM expression on the mRNA level, even without induction with tetracycline (Figure 6A). Stimulation with tetracycline in the collagen-graft resulted in an approx. 50-fold induction of EpCAM gene expression, as determined by real time PCR (Figure 6A). Interestingly, in vivo MDA-MB-231 cells re-express E-cadherin, and EpCAM overexpression represses E-cadherin gene expression (Figure 6B). Macroscopically, tumors did not differ in size after six days of in vivo growth (data not shown). We therefore performed immunohistochemical analysis of CAM sections to analyze changes on the cellular and tissue level (Figure 7A-D). MDA-MB-231 ${ }^{\text {TetR EpCAM }}$ without EpCAM overexpression were highly invasive, growing deeply into host tissue and showed only dispersed cell clusters that were weakly positive for EpCAM (Figure 7A). By comparison, EpCAM-overexpressing tumors were clearly positive for EpCAM protein expression and displayed an irregular invasion front into host tissue (Figure 7A, red line). This front was also visualized by staining for human tumor cells using cadherin (Figure 7B). EpCAM-overexpressing tumors had no compact and homogeneous invasion front into host tissue. Moreover, when analyzing the proliferation marker Ki67 EpCAM $^{\text {low }}$ tumors had a line of highly mitotic cells in the invasion front that was nearly lost in $\mathrm{EpCAM}^{\text {high }}$ tumors 

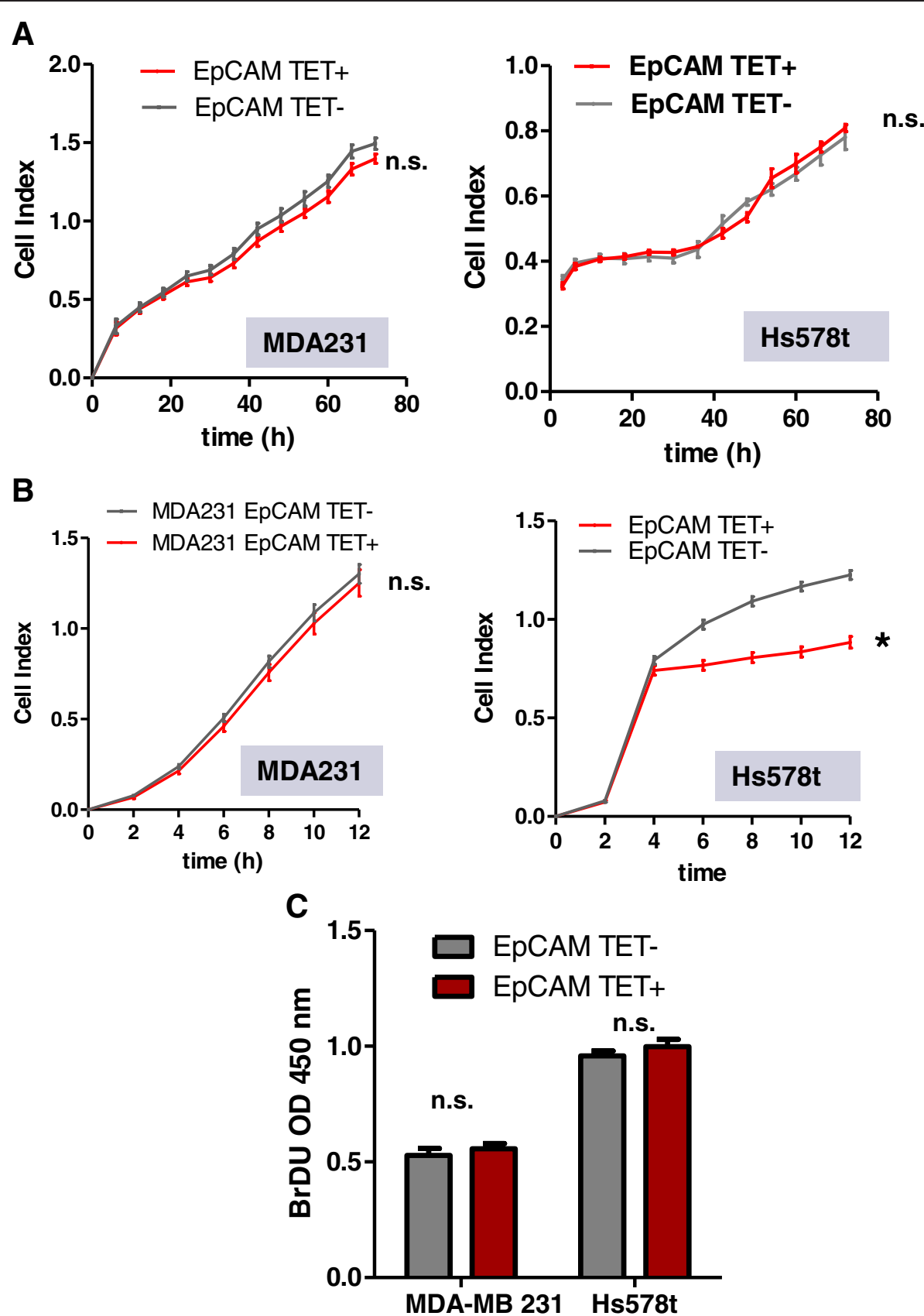

Figure 5 In vitro growth and migration of EpCAM ${ }^{\text {low }}$ human breast cancer cell lines after overexpression of EpCAM. (A) Cell numbers were determined by the xCelligence real-time system after addition of tetracycline and incubation for three days $(n=4)$. EpCAM overexpression (EPCAM TET+) did not support in vitro cell proliferation under serum-reduced culture conditions. (B) In vitro cell migration was assessed with the transwell CIM plate in the xCelligence real-time migration system $24 \mathrm{~h}$ after addition of tetracycline ( $\mathrm{n}=4)$. MDA-MB-231 TetR EpCAM cells showed no significant (n.s.) changes in cell migration after overexpression of EpCAM (EpCAM TET+). In contrast, more mesenchymal Hs578t $\mathrm{t}^{\mathrm{T}}$ etR EpCAM were significantly inhibited by overexpression of EpCAM (EpCAM TET+). (C) Cell proliferation was studied in 3D collagen plug cultures after addition of tetracycline and incubation for three days by measuring the incorporation of BrdU into synthesized DNA. Overexpression of EpCAM (EpCAM TET+) had no significant (n.s.) impact on DNA synthesis in vitro $(n=4) . *$ indicates $p$ value $<0.05$.

(Figure 7C). Inside tumors, the number of Ki67-positive cells did not differ significantly. Additionally, we stained mesenchymal human tumor cells for vimentin protein expression (Figure 7D). EpCAM ${ }^{\text {high }}$ tumors showed no differences in vimentin expression, suggesting that EpCAM overexpression did not directly affect epithelial to mesenchymal transition (EMT). Moreover, EpCAM ${ }^{\text {high }}$ tumors showed more innate immune responses from the chicken 


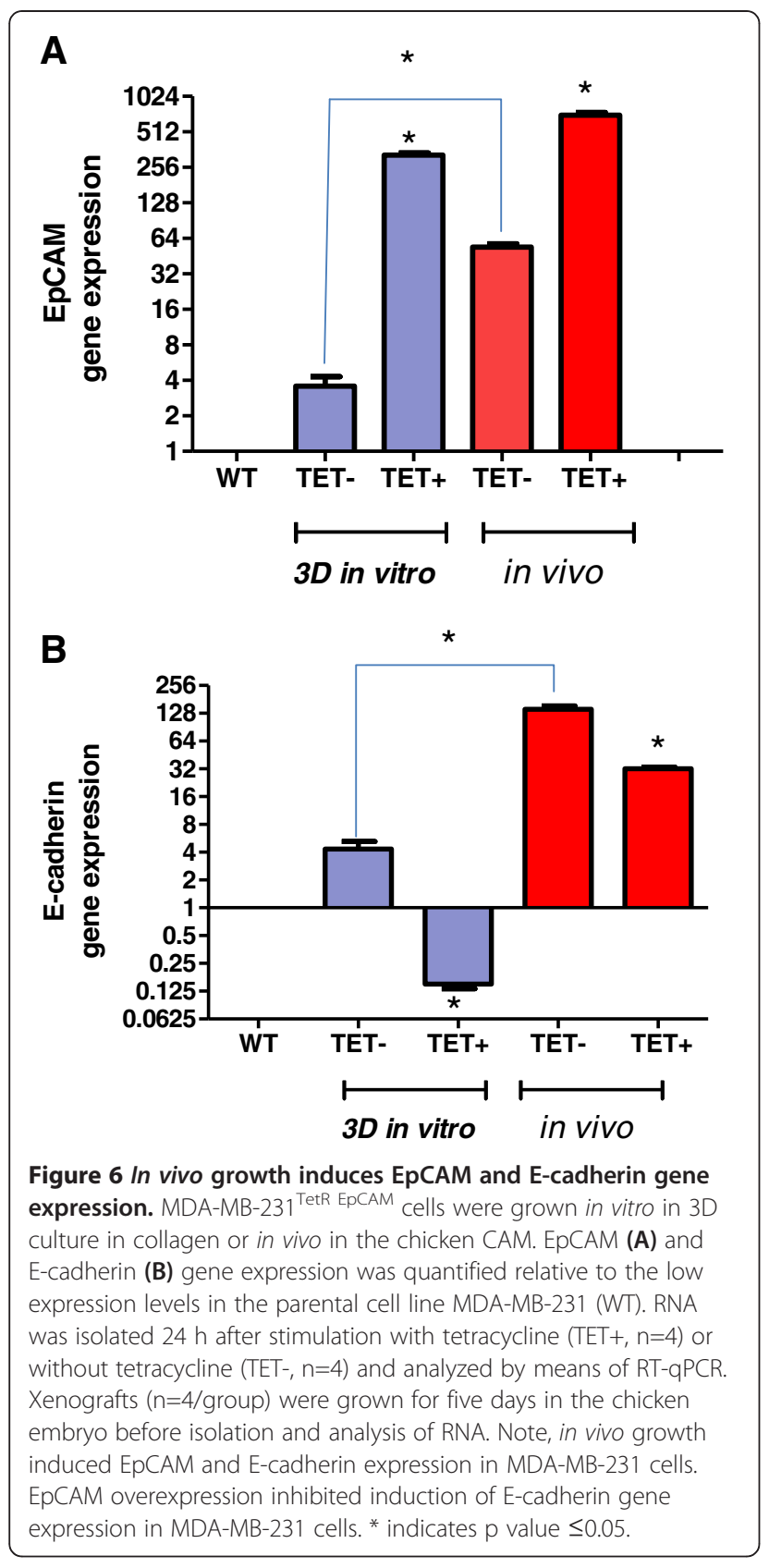

immune system. Heterophils (granulocytes) of the chicken were recruited to the tumor invasion front (blue line) and invaded in massive clusters between tumor cells (Figure 7D, yellow arrows).

\section{Discussion}

EpCAM functions as a target in antibody-based clinical trials, and the European Medicines Agency (EMA) approved in 2009 the use of the trifunctional bispecific antibody catumaxomab. In human breast cancer patients, the EpCAM-specific antibody adecatumumab shows EpCAM-dependent activity in clinical studies
[22,23]. These antibodies bind to EpCAM and enhance the immunological response to EpCAM-positive cancer cells, either in blood or malignant ascites [24]. Moreover, EpCAM has emerged as a promising target structure on cancer stem cells [25]. Cancer stem cells expressing EpCAM are more tumorigenic than EpCAM-negative stem cells $[11,26]$ and, due to their resistance to radiation and chemotherapy, targeting EpCAM might be a promising approach to impede tumor recurrence after chemo- or radiotherapy.

Whether EpCAM has a pro- or an anti-tumorigenic function in cancer appears to be dependent on the cancer type [11]. An 'ugly' role of EpCAM is reflected by studies describing both a protective and a promoting role within the very same cancer type [11]. Tumor conglomerates are very heterogeneous and contain distinct cell types. Therefore, the role of EpCAM seems to depend less on the carcinoma type, and more on the respective tumor microenvironment [11]. Thus, EpCAM can shift from a protective to a promoting role in cancer, depending on the differentiation or dedifferentiation status of epithelial cancer cells. The complex and hypothetical model of action of the EpCAM molecule is summarized in Figure 8.

This study analyzed different breast cancer cell lines, all deriving from breast cancer lymph node metastasis. In particular, it analyzed the effects of EpCAM expression on cell lines according to their phenotype, i.e. the status of epithelial to mesenchymal transition (EMT). According to their EpCAM expression profile we used lentiviral systems to alter endogenous gene expression and studied the effects on in vitro and in vivo tumor growth. Particularly, in breast carcinoma cells with high cytokeratin-18 and E-cadherin expression, i.e. epithelial phenotype, EpCAM displays growth- and invasionpromoting effects. Our data are in line with reports on pharyngeal, lung and breast cancer cells, where EpCAM seems to support tumor progression [2,11]. Indeed, in epithelial/acinar tumor cell lines with high cytokeratin expression, such as the FaDu hypopharynx carcinoma cells, EpCAM overexpression supports proliferation and cell cycle by modifying Wnt signaling [27]. Moreover, a recent study by Maghazal et al. showed that EpCAM signaling is important during embryogenesis [28]. Independently of its putative cell adhesion function, EpCAM strongly supports cell movements and mixing of tissues by a protein kinase $\mathrm{C}$-dependent signaling mechanism.

Hs578t and MDA-MB-231 cells with a more mesenchymal phenotype do not gain survival benefits from EpCAM overexpression or signaling. These cells typically have low EpCAM and E-cadherin expression and display invasive growth and migration like reactive fibroblasts $[10,29]$. Our findings are in line with those of early studies by Litvinov and colleagues on fibroblast-like cells. They found that overexpression of EpCAM in vivo 


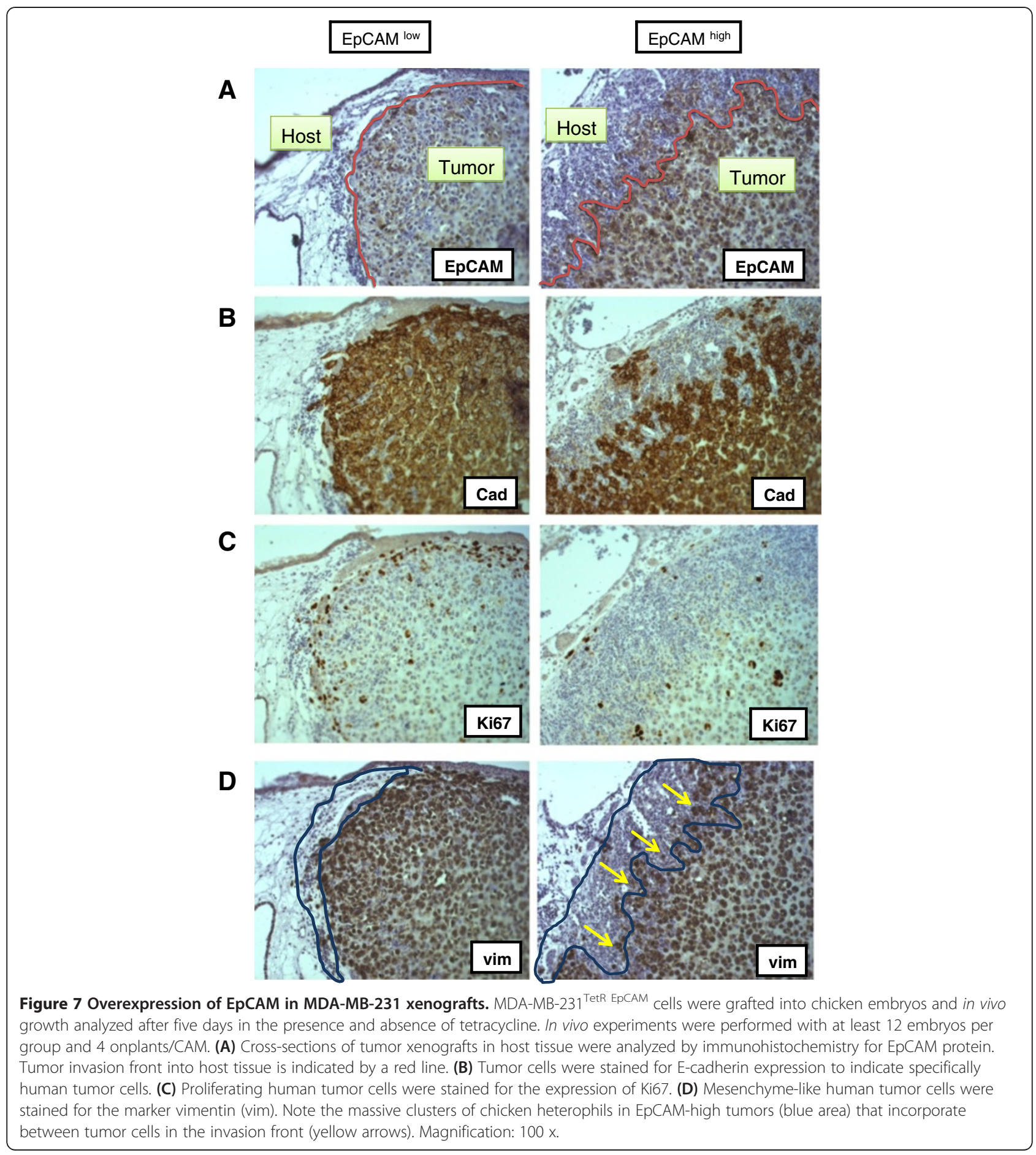

inhibited the invasive growth of fibroblastic L cells and dedifferentiated mammary carcinoma L153S cells. Moreover, EpCAM overexpression suppressed invasive colony growth of fibroblastic L cells in EHS matrigel in vitro [30]. Interestingly, EpCAM overexpression did not support mesenchymal-to-epithelial reverting transition (MErT). However, MDA-MB-231 cells started to reexpress E-cadherin in vivo in our xenograft model, a fact already observed by Chao et al. [31]. This MErT process was not affected by overexpression of EpCAM. Xenografts still retained the high vimentin expression, but EpCAMoverexpressing tumors displayed massive infiltrations of chicken heterophils, which are avian analogs of mammalian neutrophils [32]. In addition, few monocytes/macrophages avian heterophils are recruited to areas of inflammation and to the invading tumor cell front, thereby strongly 


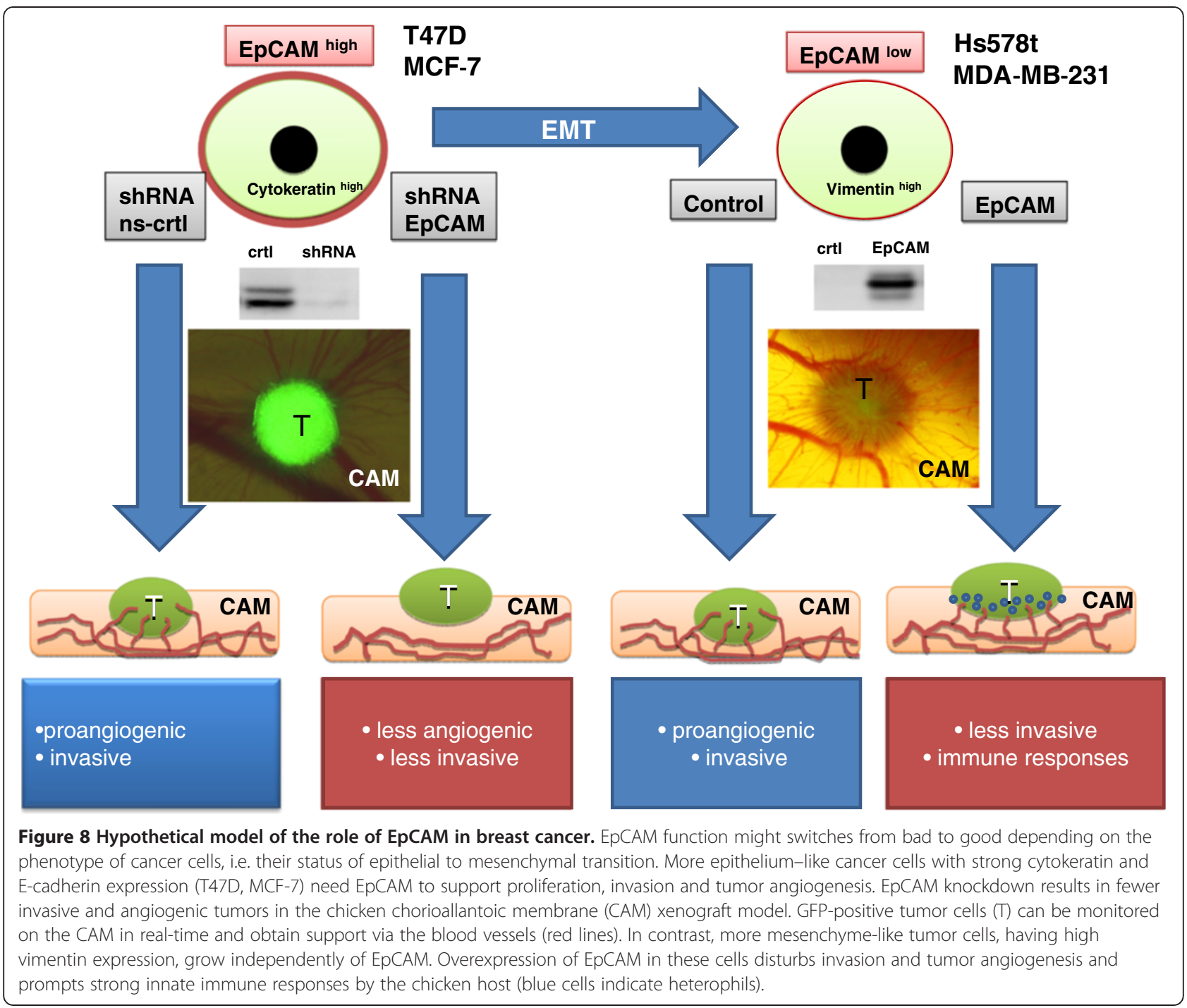

promoting angiogenesis [33]. Thus, EpCAM overexpression in mesenchyme-like tumors seems to stimulate inflammatory processes by activating and attracting neutrophils to the invasion front. Tumorassociated neutrophils (TANs) can promote the progression of primary tumors [34]. However, depending on TGF- $\beta$ signaling TAN can also differentiate into a population with antitumor activity [35]. Recently, it was reported that neutrophils in tumor-bearing subjects can act to eliminate disseminated tumor cells and thus provide antimetastatic protection [36].

Most importantly, all these findings might even have a clinical impact since EpCAM-based targeting agents (i.e. catumaxomab) are now available for therapeutic use also in breast cancer patients [24]. In fact, breast cancer is a frequent cause of malignant ascites and especially invasive lobular breast cancer patients develop peritoneal carcinomatosis with malignant ascites [37]. However, EpCAM expression is usually low in lobular breast cancer as compared to ductal cancer [38], and the phenotype of lobular breast cancer resembles that of cancer cells undergoing EMT described in the present study. Considering our data on an antitumorigenic effect of EpCAM in mesenchyme-like cancer cells, targeting EpCAM in patients with lobular breast cancer might even result in a counterproductive effect. For this reason, particular attention should be given to clinical studies determining the efficacy of EpCAM-targeting agents in the subgroup of patients with lobular breast cancer.

\section{Conclusion}

The role of EpCAM in breast cancer changes with tumor cell phenotype and the respective tumor microenvironment. Cancer cells with an epithelial phenotype use EpCAM overexpression and signaling for growth and invasion. In contrast, in tumor cells with a mesenchymal phenotype EpCAM expression 
decreases and the tumor cells grow independently of EpCAM signaling. Re-expression of EpCAM in these tumors inhibits migration and invasion and promotes inflammation and innate immune responses. Therefore, the fact that EpCAM has a dual role in tumorigenesis should be given consideration when planning EpCAM-targeted therapies in breast cancer patients.

\section{Competing interests}

The authors declare that they have no competing interests.

\section{Authors' contributions}

AM established lentiviral constructs, transfected cell lines, carried out migration and proliferation assays, animal experiments and contributed substantially to the experimental design. GU planned experiments and drafted the manuscript. GS and GG participated in study design and data interpretation. All authors read and approved the final manuscript.

\section{Acknowledgements}

This work was performed in the framework of AM's PhD program in Molecular Cell Biology and Oncology (MCBO) and was supported by the Austrian Science Fund (FWF Grant No. P19552).

\section{Author details}

${ }^{1}$ Laboratory of Experimental Oncology, Tyrolean Cancer Research Institute, Innsbruck, Austria. ${ }^{2}$ Day Hospital of Haematology and Oncology, Franz Tappeiner Hospital, Merano, Italy. ${ }^{3}$ Laboratory of Tumor Biology and Angiogenesis, Department of Internal Medicine $V$, Innsbruck Medical University, Innsbruck, Austria.

Received: 3 July 2012 Accepted: 25 October 2012

Published: 30 October 2012

\section{References}

1. Herlyn M, Steplewski Z, Herlyn D, Koprowski H: Colorectal carcinomaspecific antigen: detection by means of monoclonal antibodies. Proc Natl Acad Sci U S A 1979, 76:1438-1442.

2. Baeuerle PA, Gires O: EpCAM (CD326) finding its role in cancer. Br J Cancer 2007, 96:417-423.

3. Gosens MJ, van Kempen LC, van de Velde CJ, van Krieken JH, Nagtegaal ID: Loss of membranous Ep-CAM in budding colorectal carcinoma cells. Mod Pathol 2007, 20:221-232.

4. Munz M, Fellinger K, Hofmann T, Schmitt B, Gires O: Glycosylation is crucial for stability of tumour and cancer stem cell antigen EpCAM. Front Biosci 2008, 13:5195-5201.

5. Pauli C, Munz M, Kieu C, Mack B, Breinl P, Wollenberg B, Lang S, Zeidler R, Gires O: Tumor-specific glycosylation of the carcinomaassociated epithelial cell adhesion molecule EpCAM in head and neck carcinomas. Cancer Lett 2003, 193:25-32.

6. Schmidt M, Hasenclever D, Schaeffer M, Boehm D, Cotarelo C, Steiner E, Lebrecht A, Siggelkow W, Weikel W, Schiffer-Petry I, et al: Prognostic effect of epithelial cell adhesion molecule overexpression in untreated nodenegative breast cancer. Clin Cancer Res 2008, 14:5849-5855.

7. Gastl G, Spizzo G, Obrist P, Dunser M, Mikuz G: Ep-CAM overexpression in breast cancer as a predictor of survival. Lancet 2000, 356:1981-1982.

8. Spizzo G, Went P, Dirnhofer S, Obrist P, Simon R, Spichtin H, Maurer R, Metzger $U$, von CB, Bart $R$, et al: High Ep-CAM expression is associated with poor prognosis in node-positive breast cancer. Breast Cancer Res Treat 2004, 86:207-213.

9. Cimino A, Halushka M, Illei P, Wu X, Sukumar S, Argani P: Epithelial cell adhesion molecule (EpCAM) is overexpressed in breast cancer metastases. Breast Cancer Res Treat 2010, 123:701-708.

10. Tomaskovic-Crook E, Thompson EW, Thiery JP: Epithelial to mesenchymal transition and breast cancer. Breast Cancer Res 2009, 11:213.

11. van der Gun BT, Melchers LJ, Ruiters MH, de Leij LF, McLaughlin PM, Rots MG: EpCAM in carcinogenesis: the good, the bad or the ugly. Carcinogenesis 2010, 31:1913-1921.
12. Petersen $\mathrm{OW}$, Nielsen $H L$, Gudjonsson $T$, Villadsen R, Rank F, Niebuhr $E_{\text {, }}$ Bissell MJ, Ronnov-Jessen L: Epithelial to mesenchymal transition in human breast cancer can provide a nonmalignant stroma. Am J Pathol 2003, 162:391-402

13. Dandachi N, Hauser-Kronberger C, More E, Wiesener B, Hacker GW, Dietze $\mathrm{O}$, Wirl G: Co-expression of tenascin-C and vimentin in human breast cancer cells indicates phenotypic transdifferentiation during tumour progression: correlation with histopathological parameters, hormone receptors, and oncoproteins. J Pathol 2001, 193:181-189.

14. Sorlie T, Perou CM, Tibshirani R, Aas T, Geisler S, Johnsen H, Hastie T, Eisen $M B$, van de Rijn M, Jeffrey SS, et al: Gene expression patterns of breast carcinomas distinguish tumor subclasses with clinical implications. Proc Natl Acad Sci U S A 2001, 98:10869-10874.

15. Frederick BA, Helfrich BA, Coldren CD, Zheng D, Chan D, Bunn PA Jr, Raben $D$ : Epithelial to mesenchymal transition predicts gefitinib resistance in cell lines of head and neck squamous cell carcinoma and non-small cell lung carcinoma. Mol Cancer Ther 2007, 6:1683-1691.

16. Santisteban M, Reiman JM, Asiedu MK, Behrens MD, Nassar A, Kalli KR, Haluska P, Ingle JN, Hartmann LC, Manjili MH, et al: Immune-induced epithelial to mesenchymal transition in vivo generates breast cancer stem cells. Cancer Res 2009, 69:2887-2895.

17. Jojovic M, Adam E, Zangemeister-Wittke U, Schumacher U: Epithelial glycoprotein-2 expression is subject to regulatory processes in epithelialmesenchymal transitions during metastases: an investigation of human cancers transplanted into severe combined immunodeficient mice. Histochem J 1998, 30:723-729.

18. Geraerts M, Willems S, Baekelandt V, Debyser Z, Gijsbers R: Comparison of lentiviral vector titration methods. BMC Biotechnol 2006, 6:34.

19. Pfaffl MW: A new mathematical model for relative quantification in real-time RT-PCR. Nucleic Acids Res 2001, 29:e45.

20. Deryugina El, Quigley JP: Chick embryo chorioallantoic membrane mode systems to study and visualize human tumor cell metastasis. Histochem Cell Biol 2008, 130:1119-1130.

21. Ribatti D, Nico B, Cimpean AM, Raica M, Crivellato E, Ruggieri S, Vacca A: B16-F10 melanoma cells contribute to the new formation of blood vessels in the chick embryo chorioallantoic membrane through vasculogenic mimicry. Clin Exp Med 2012.

22. Schmidt M, Scheulen ME, Dittrich C, Obrist P, Marschner N, Dirix L, Schmidt M, Ruttinger D, Schuler M, Reinhardt C, et al: An open-label, randomized phase II study of adecatumumab, a fully human antiEpCAM antibody, as monotherapy in patients with metastatic breast cancer. Ann Oncol 2010, 21:275-282.

23. Schmidt M, Ruttinger D, Sebastian M, Hanusch CA, Marschner N, Baeuerle PA, Wolf A, Goppel G, Oruzio D, Schlimok G, et al: Phase IB study of the EpCAM antibody adecatumumab combined with docetaxel in patients with EpCAM-positive relapsed or refractory advanced-stage breast cancer. Ann Oncol 2012, 28:2306-2313.

24. Bokemeyer C: Catumaxomab-trifunctional anti-EpCAM antibody used to treat malignant ascites. Expert Opin Biol Ther 2010, 10:1259-1269.

25. Gires $\mathrm{O}$, Klein CA, Baeuerle PA: On the abundance of EpCAM on cancer stem cells. Nat Rev Cancer 2009, 9:143.

26. Munz M, Baeuerle PA, Gires O: The emerging role of EpCAM in cancer and stem cell signaling. Cancer Res 2009, 69:5627-5629.

27. Maetzel D, Denzel S, Mack B, Canis M, Went P, Benk M, Kieu C, Papior P, Baeuerle PA, Munz M, et al: Nuclear signalling by tumour-associated antigen EpCAM. Nat Cell Biol 2009, 11:162-171.

28. Maghzal N, Vogt E, Reintsch W, Fraser JS, Fagotto F: The tumorassociated EpCAM regulates morphogenetic movements through intracellular signaling. J Cell Biol 2010, 191:645-659.

29. Blick T, Widodo E, Hugo H, Waltham M, Lenburg ME, Neve RM, Thompson EW: Epithelial mesenchymal transition traits in human breast cancer cell lines. Clin Exp Metastasis 2008, 25:629-642.

30. Litvinov SV, Velders MP, Bakker HA, Fleuren GJ, Warnaar SO: Ep-CAM: a human epithelial antigen is a homophilic cell-cell adhesion molecule. J Cell Biol 1994, 125:437-446.

31. Chao YL, Shepard CR, Wells A: Breast carcinoma cells re-express Ecadherin during mesenchymal to epithelial reverting transition. Mol Cancer 2010, 9:179.

32. Harmon BG: Avian heterophils in inflammation and disease resistance. Poult Sci 1998, 77:972-977. 
33. Zijlstra A, Seandel M, Kupriyanova TA, Partridge JJ, Madsen MA, HahnDantona EA, Quigley JP, Deryugina El: Proangiogenic role of neutrophillike inflammatory heterophils during neovascularization induced by growth factors and human tumor cells. Blood 2006, 107:317-327.

34. Cortez-Retamozo V, Etzrodt M, Newton A, Rauch PJ, Chudnovskiy A, Berger C, Ryan RJ, Iwamoto Y, Marinelli B, Gorbatov R, et al: Origins of tumor-associated macrophages and neutrophils. Proc Natl Acad Sci U S A 2012, 109:2491-2496.

35. Fridlender ZG, Sun J, Kim S, Kapoor V, Cheng G, Ling L, Worthen GS, Albelda SM: Polarization of tumor-associated neutrophil phenotype by TGF-beta: "N1" versus "N2" TAN. Cancer Cell 2009, 16:183-194.

36. Granot Z, Henke E, Comen EA, King TA, Norton L, Benezra R: Tumor entrained neutrophils inhibit seeding in the premetastatic lung. Cancer Cell 2011, 20:300-314.

37. Ayantunde AA, Parsons SL: Pattern and prognostic factors in patients with malignant ascites: a retrospective study. Ann Oncol 2007, 18:945-949.

38. Spizzo G, Fong D, Wurm M, Ensinger C, Obrist P, Hofer C, Mazzoleni G, Gastl $G$, Went P: EpCAM expression in primary tumour tissues and metastases: an immunohistochemical analysis. J Clin Pathol 2011, 64:415-420.

doi:10.1186/1471-2407-12-501

Cite this article as: Martowicz et al:: Phenotype-dependent effects of

EpCAM expression on growth and invasion of human breast cancer cell lines. BMC Cancer 2012 12:501.

\section{Submit your next manuscript to BioMed Central and take full advantage of:}

- Convenient online submission

- Thorough peer review

- No space constraints or color figure charges

- Immediate publication on acceptance

- Inclusion in PubMed, CAS, Scopus and Google Scholar

- Research which is freely available for redistribution 